\title{
RÉGIMEN DE PROTECCIÓN DE LOS ADULTOS MAYORES EN LA PROVINCIA DE CORRIENTES, ARGENTINA
}

PROTECTION OF OLDER ADULTS IN THE PROVINCE OF CORRIENTES, ARGENTINA

\section{MAURICIO GOLDFARB}

Facultad de Derecho y Ciencias Sociales y Políticas Universidad Nacional del Nordeste

ARGENTINA

Los mayores necesitan un objetivo, no sólo recreación. Los mayores necesitan un sueño, no sólo memoria.. Abraham Joshua Heschel 
pesar de la importancia cada vez mayor en términos relativos de la población de adultos mayores, son escasos los estudios doctrinarios sobre la materia en el ámbito local, déficit que este artículo intenta disminuir. Para ello se analiza el sistema normativo provincial, sin omitir la consideración del régimen de tutela especial del orden federal. En particular, se hace foco en la operatividad de ciertos derechos y su exigibilidad por los titulares de los derechos y sus familias, con referencias a la jurisprudencia más relevante. En el capítulo final se realiza una evaluación general del sistema de tutela y se exponen las conclusiones del trabajo.

Palabras Clave: derechos humanos, adultos mayores, obras sociales, acompañantes terapéuticos.

\begin{abstract}
Despite the growing importance in relative terms of the population of older adults, there are few doctrinal studies on the subject at the local level, a deficit that this article attempts to reduce. For this, the provincial normative system is analyzed, without omitting the consideration of the special protection regime of the federal order. In particular, it focuses on the operation of certain rights and their enforceability by the holders of rights and their families, with references to the most relevant jurisprudence. In the final chapter a general evaluation of the guardianship system is made and the conclusions of the work are exposed.
\end{abstract}

Keywords: human rights, older adults, social security, therapeutic companions.

\title{
1.- INTRODUCCIÓN
}

El presente artículo propone una revisión del sistema de protección de los derechos de los adultos mayores en la provincia de Corrientes (Argentina). La importancia en términos relativos de la población de adultos mayores es cada vez mayor. Según la Organización de las Naciones Unidas, en América Latina y el Caribe el grupo poblacional de personas mayores de 60 años alcanzaba en 2012 a 57 millones y llegará a 180 millones en 2050 (más de una cuarta parte del total). En nuestro país, los mayores de 60 años representan un 14,3\% de la población 
(casi 6 millones de personas) según los datos del último Censo realizado en 2010. El grupo etario muestra un claro predominio femenino: 57\% contra 43\% de hombres (INDEC, 2014 p.7). En el caso de la provincia de Corrientes, el porcentaje total de adultos mayores es algo menor que el promedio nacional y alcanza solo al $11,29 \%{ }^{1}$

Además de aumentar -en términos absolutos y relativos- el número de las personas mayores, también se extiende su expectativa de vida. Así, la esperanza de vida al nacer en nuestra región, que en 1950 era de 51 años, alcanzó en promedio los 75 años en 2010 y los estudios pronostican que seguirá incrementándose (Huenchuan, 2012 p. 12). Este aumento del número de ancianos y el incremento de la esperanza de vida, genera modificaciones en el ámbito familiar y social y complejos desafíos a las autoridades estatales. Especialmente, en lo referido a la cantidad y calidad de las prestaciones que el Estado debe brindar, en materia previsional y de salud para el pleno ejercicio de los derechos fundamentales. Esta tutela especial de los derechos de las personas mayores ha dado lugar a lo que varios autores han considerado ya como una nueva especialidad del derecho y que brinda el marco teórico a este trabajo: el derecho de la vejez o derecho de la ancianidad, como disciplina que estudia la condición jurídica de las personas mayores de sesenta años en el derecho interno y supranacional y las herramientas de protección y garantía de sus derechos (Davobe, 2015 p. 9).

El esquema que proponemos es revisar el marco normativo supranacional, nacional y provincial, considerando como unidad de análisis a la provincia de Corrientes. La metodología empleada es principalmente descriptiva y cualitativa, abordando tanto los aspectos normativos como los relacionados con la efectividad de los derechos sociales. No obstante, se incluyen datos objetivos y cuantitativos para una mejor comprensión del objeto de análisis. El estudio está también especialmente orientado a considerar, más allá del reconocimiento normativo, los criterios interpretativos que deben seguirse ante posibles dudas en la aplicación de las normas, y las reales posibilidades de tutela efectiva de los derechos por parte de los adultos mayores y sus familias. En el desarrollo se enumeran los principales derechos reconocidos, así como posibles conflictos que pueden generarse respecto de su alcance. Si bien el objetivo del trabajo es principalmente descriptivo, se subrayan algunas dificultades que aparecen en el ejercicio de los derechos, más allá de su reconocimiento formal, recurriendo a la jurisprudencia más destacada en la materia. Finalmente, en el último capítulo, exponemos las conclusiones del trabajo.

\section{LA TUTELA ESPECIAL DE LOS ADULTOS MAYORES EN EL ORDEN CONSTITUCIONAL Y SUPRANACIONAL}

El artículo 16 de la Constitución Nacional reconoce un principio estructural de nuestro orden jurídico: La igualdad ante la ley. Pero esta igualdad formal no puede desconocer las pro-

${ }_{1}^{1}$ https://www.indec.gob.ar/ftp/censos/2010/CuadrosDefinitivos/P2-P_Corrientes.pdf 
fundas diferencias que existen entre cada uno de los integrantes de la sociedad. Las distintas condiciones de género, edad, ingresos, educación y salud determinan que haya sectores con oportunidades reales muy distintas entre sí. Como señala Davobe, existe una evolución desde una concepción abstracta y general de la persona como sujeto a quien se le reconocen derechos, a una versión más material y positiva, a proteger al ser humano situado, reconociendo categorías que son relevantes a los efectos jurídicos (Davobe 2002, p. 436).

El paso de una igualdad formal a una igualdad real de oportunidades que garantice el goce de los derechos reconocidos en la Constitución solo es posible con medidas de acción positiva a cargo del Estado. Es en este sentido que la reforma constitucional de 1994 incluyó un mandato explícito al Congreso de la Nación: "Legislar y promover medidas de acción positiva que garanticen la igualdad real de oportunidades y de trato, y el pleno goce y ejercicio de los derechos reconocidos por esta Constitución y por los tratados internacionales vigentes sobre derechos humanos, en particular respecto de los niños, las mujeres, los ancianos y las personas con discapacidad". ${ }^{2}$ De este modo, el constituyente identificó cuatro grupos que requieren una tutela especial y diferenciada: los niños, las mujeres, los ancianos y las personas con discapacidad. Estas medidas incluyen las llamadas acciones positivas o de discriminación inversa, por las cuales el Estado facilita el acceso a los derechos constitucionales a sectores menos favorecidos (Gelli 2013, p. 235).

En cumplimiento parcial de la manda constitucional el Congreso fue dictando normas de tutela muy importantes, como la ley 24.091 de Sistema de Prestaciones Básicas y rehabilitación integral de las personas con discapacidad (1997), la ley 26.061 de Protección Integral de los niños, niñas y adolescentes (2005) y la ley 26.485 de Protección Integral para prevenir, sancionar y erradicar la violencia contra las mujeres (2009). En el orden supranacional, el parlamento nacional ratificó además la Convención Interamericana para prevenir, sancionar y erradicar la violencia contra la mujer (Ley 24.362 del 13 de marzo de 1996) y la Convención Interamericana para la eliminación de toda forma de discriminación contra las personas con discapacidad (Ley 25.280 del 6 de julio de 2000).

Sin embargo, y respecto de nuestro objeto de estudio, no fue sino hasta 2017 con la sanción de la ley 27.360, ${ }^{3}$ por la cual el Congreso de la Nación ratificó la Convención Interamericana sobre Protección de los Derechos Humanos de las Personas Mayores, (en adelante la Convención) que el estado nacional cumplió la manda constitucional respecto de la protección de los adultos mayores. La Convención fue adoptada por la Organización de los Estados Americanos durante la $45^{\circ}$ Asamblea General de la OEA, el 15 de junio de 2015. Hasta agosto de 2018 ha sido ratificada por Argentina, ${ }^{4}$ Bolivia, Chile, Costa Rica, El Salvador y Uruguay. ${ }^{5}$ La

\footnotetext{
${ }^{2}$ Artículo 75 inciso 23 incorporado en la Reforma de 1994.

${ }^{3}$ Publicada el 31 de mayo de 2017 en el Boletín Oficial de la Nación.

${ }^{4}$ El 27 de octubre de 2017 el gobierno argentino cumplió con el último trámite para la vigencia de la Convención: el depósito del instrumento de ratificación ante la sede de la OEA.

${ }^{5} \mathrm{http}: / /$ www.oas.org/es/sla/ddi/tratados_multilaterales_interamericanos_A-70_derechos_humanos_personas_mayores_firmas.asp
} 
Convención entró en vigencia el 11 de enero de 2017, el trigésimo día a partir de la fecha en que se depositó el segundo instrumento de ratificación en la Secretaría General de la Organización de los Estados Americanos.

Este nuevo tratado es la más reciente incorporación del Sistema Interamericano de Protección de los Derechos Humanos, conformado por la Declaración Americana de los Derechos del Hombre (1948), la Convención Americana sobre Derechos Humanos (1969), la Convención Interamericana para Prevenir y Sancionar la Tortura (1985), el Protocolo de San Salvador en Materia de Derechos Económicos, Sociales y Culturales (1988), la Convención Interamericana para Prevenir, Sancionar y Erradicar la Violencia contra la Mujer (1994), la Convención Interamericana sobre Desaparición Forzada de Personas (1994), la Convención Interamericana para la Eliminación de Toda Forma de Discriminación contra las Personas con Discapacidad (1999) y la Convención Interamericana contra Toda Forma de Discriminación e Intolerancia (2013).

En el orden global, la tutela de los adultos mayores tampoco es una iniciativa aislada. Como lo recuerda el propio preámbulo de la Convención, la comunidad internacional ya señaló la importancia del tema en los Principios de las Naciones Unidas en favor de las Personas de Edad (1991), la Proclamación sobre el Envejecimiento (1992), la Declaración Política y el Plan de Acción Internacional de Madrid sobre el Envejecimiento (2002), la Estrategia Regional de implementación para América Latina y el Caribe del Plan de Acción Internacional de Madrid sobre el Envejecimiento (2003), la Declaración de Brasilia (2007), el Plan de Acción de la Organización Panamericana de la Salud sobre la salud de las personas mayores, incluido el envejecimiento activo y saludable (2009), la Declaración de Compromiso de Puerto España (2009) y la Carta de San José sobre los derechos de las personas mayores de América Latina y el Caribe (2012) entre otros documentos.

Además de estos antecedentes supranacionales, existe también un precedente constitucional, muchas veces olvidado tal vez por su corta vigencia. En la reforma constitucional de 1949 se reconocieron expresamente los derechos de las personas mayores, incluyendo en el artículo 37 (Derechos del trabajador, de la familia, de la ancianidad y de la educación y la cultura) un capítulo III llamado "De la ancianidad". En dicho capítulo, el constituyente reconocía expresamente como derechos especiales de las personas mayores:

1. El derecho a la asistencia, como derecho a su protección integral, por cuenta y cargo de su familia. Sin embargo, supletoriamente, encargaba al Estado proveer a su protección, ya sea en forma directa o por intermedio de las instituciones creadas con ese fin, sin perjuicio de la subrogación, para demandar a los familiares remisos los aportes correspondientes.

2. El derecho a la vivienda, consistente en un albergue higiénico, con un mínimo de comodidades hogareñas.

3. El derecho a la alimentación sana, y adecuada a la edad y estado físico.

4. El derecho a un vestido decoroso y apropiado al clima. 
5. El derecho al cuidado de la salud física y moral, incluyendo el libre ejercicio de su culto religioso.

6. El derecho al esparcimiento.

7. El derecho al trabajo.

8. El derecho a la tranquilidad.

9. El derecho al respeto.

Otras normas nacionales que también se aplican de modo directo a los adultos mayores son la ley 24.417 y la ley 26.742. La ley 24.417 de protección contra la violencia familiar (1994) prevé para el caso de los ancianos (y los niños y discapacitados) legitimación no solo al afectado, sino también al ministerio público y a cualquier funcionario público para la tutela de sus derechos. En materia de salud, la legislación nacional argentina también incluye de modo expreso el derecho a recibir cuidados paliativos integrales como parte de la atención a la enfermedad, derecho consagrado en el orden federal desde 2009 con la Ley 26.742 (Ley de Derechos del Paciente). ${ }^{6}$ Sin embargo, como consecuencia del sistema federal argentino, la aplicación de esta norma queda sujeta a las modalidades que reglamenten las administraciones provinciales. De todos modos, la Convención posee una diferencia importante con otros instrumentos supranacionales respecto de su efectividad en las jurisdicciones locales (la llamada cláusula federal). Así, en su artículo 1 in fine la Convención establece expresamente que "Las disposiciones de la presente Convención se aplicarán a todas las partes de los Estados federales sin limitaciones ni excepciones". ${ }^{7}$

Sin perjuicio de esta aplicación amplia, la Corte Federal ya tuvo oportunidad de señalar en Campodónico de Beviqua ${ }^{8}$ que más allá de la distribución de competencias entre el Estado federal y las provincias, le corresponde al Estado nacional garantizar los derechos consagrados en los tratados internacionales, en particular con relación al derecho a la salud. Por ello, el Estado nacional no puede excusarse en el incumplimiento de las jurisdicciones provinciales para no garantizar un derecho reconocido internacionalmente.

\footnotetext{
${ }^{6} \mathrm{http}: / /$ servicios.infoleg.gob.ar/infolegInternet/anexos/160000-164999/160432/norma.htm

${ }^{7}$ Esta aplicación sin restricciones la diferencia de la Convención Interamericana de Derechos Humanos, que en su artículo 28 (Cláusula Federal), establece dos planos distintos de responsabilidad internacional al estado Federal: El gobierno nacional debe cumplir todas las disposiciones de la Convención relacionadas con las materias sobre las que ejerce jurisdicción legislativa y judicial. Sin embargo, respecto a las disposiciones relativas a las materias que corresponden a la jurisdicción de las provincias, el gobierno nacional debe tomar las medidas conforme a la constitución y las leyes para que las autoridades locales cumplan con la Convención.

${ }^{8}$ Campodónico de Beviacqua, Ana Carina c/ Ministerio de Salud y Acción Social s/Amparo, sentencia del 24/10/00. En el caso, se reclamaba la cobertura farmacológica para un niño con una grave discapacidad. La Corte confirmó una sentencia de Cámara y condenó al Estado Nacional a mantener la provisión de medicamentos al niño. El gobierno había entregado previamente los medicamentos, pero había anunciado su intención interrumpir la entrega, alegando no estar legalmente obligado a ello.
} 


\section{LOS ADULTOS MAYORES COMO SUJETOS VULNERABLES}

En los últimos años se ha reconocido con fuerza la categoría de sujetos vulnerables como una forma de garantizar el ejercicio pleno de los derechos de las personas incluidas en grupos sociales especialmente afectados. Las 100 Reglas de Brasilia sobre Acceso a la Justicia de las Personas en Condición de Vulnerabilidad ${ }^{9}$ han reconocido especialmente esta situación. En la Regla 3 se incluye en el concepto de vulnerables a aquellas personas que, por razón de "su edad, género, estado físico o mental, o por circunstancias sociales, económicas, étnicas y/o culturales, encuentran especiales dificultades para ejercitar con plenitud ante el sistema de justicia los derechos reconocidos por el ordenamiento jurídico”. La Regla 4 complementa el concepto y enumera las posibles causas de vulnerabilidad: "Podrán constituir causas de vulnerabilidad, entre otras, las siguientes: la edad, la discapacidad, la pertenencia a comunidades indígenas o a minorías, la victimización, la migración y el desplazamiento interno, la pobreza, el género y la privación de libertad. La concreta determinación de las personas en condición de vulnerabilidad en cada país dependerá de sus características específicas, o incluso de su nivel de desarrollo social y económico".

La condición de vulnerable es entonces una situación que debe analizarse en cada país y en cada caso particular, sin mayores dificultades. En especial, porque en nuestras sociedades latinoamericanas es muy común el caso de vulnerabilidad múltiple: pobreza, discapacidad, género y analfabetismo suelen determinar condiciones que se conjugan, agravan y potencian.

Las Reglas de Brasilia también contienen una consideración especial a la vulnerabilidad por edad. La Regla 6 establece que: "El envejecimiento también puede constituir una causa de vulnerabilidad cuando la persona adulta mayor encuentre especiales dificultades, atendiendo a sus capacidades funcionales, para ejercitar sus derechos ante el sistema de justicia”. Además, como ya hemos visto, esta condición de vulnerable de las personas mayores puede verse fuertemente potenciada por inconvenientes de salud, económicos o culturales que agraven su situación. La ancianidad implica un deterioro característico de esa etapa de la vida, la cual puede afectar no solo aspectos físicos sino también cognitivos o de otro tipo, así como la aparición de patologías comunes a todas las edades o exclusivas o con mayor prevalencia en la vejez (p.e. Mal de Alzheimer). En este sentido, Davobe resalta que debe diferenciarse el desarrollo de una ancianidad normal, de aquella que reviste carácter de frágil -asociada con alguna enfermedad o discapacidad- de la ancianidad patológica, en la que la enfermedad es el aspecto central de la condición del anciano (Davobe 2015, p. 12).

La Corte Suprema de Justicia de la Nación ha utilizado el carácter de vulnerables de los adultos mayores como fundamento para sus decisiones. Por ejemplo, en los autos Constantino, Eduardo F. c/ANSeS s/Reajustes Varios. ${ }^{10}$ En el caso se discutía la competencia para

\footnotetext{
${ }_{9}^{9}$ Aprobadas en la XIV Cumbre Judicial Iberoamericana realizada en Brasilia en 2008. Texto completo disponible en http://www. acnur.org/fileadmin/Documentos/BDL/2009/7037.pdf

${ }^{10}$ Sentencia del 07/06/16, Considerando 4.
} 
entender en los recursos de apelación interpuestos por ANSeS en causas tramitadas ante los Juzgados Federales del interior del país (si correspondía a la Cámara Federal de la Seguridad Social -como parecía resultar de la letra de la ley- o las Cámaras Federales con competencia en cada provincia). Los ministros del tribunal tuvieron en cuenta que, como consecuencia de "la política recursiva indiscriminada que aplica la ANSeS, cuyo efecto multiplicador abarrota de apelaciones a las tres salas de la Cámara Federal de la Seguridad Social, y las dificultades que evidencia esa cámara para resolver el universo de expedientes que tiene a examen" resultaba necesario proceder a ampliar el desplazamiento de causas hacia las Cámaras Federales con asiento en las provincias, ampliando la regla de competencia sentada en la causa Pedraza, Héctor Hugo c/ANSeS s/Acción de Amparo. ${ }^{11}$ Así dispuso la remisión -sin excepciones- de todos los juicios previsionales que hubiesen tramitado ante los juzgados federales con asiento en las provincias hacia las Cámaras Federales que resulten competentes en razón de territorio, sin que pudiera invocarse contra esta medida la radicación previa ante la Cámara Federal de la Seguridad Social. Para decidir sobre el tribunal competente, la Corte destacó que: "Sin perjuicio de resaltar que esa solución era la que mejor se adecuaba al principio federal de nuestro Estado, resultaba más conveniente que los litigios se desarrollasen en los tribunales cercanos al domicilio del jubilado, que vale recordarlo, constituye un grupo vulnerable de preferente tutela de acuerdo a la Constitución Nacional (art. 75, inc. 23)". De lo contrario, se vería seriamente afectado su derecho a ocurrir ante un órgano judicial en procura de justicia, consagrado en el artículo 18 de la Constitución Nacional y que requiere que la tutela judicial de los derechos en cuestión resulte efectiva, esto es, oportuna y que posea la virtualidad de resolver definitivamente la cuestión (Convención Americana sobre Derechos Humanos, artículos 8 y 25.2.a y del Pacto Internacional de Derechos Civiles y Políticos, artículo 14.1).

En el orden internacional, también la Corte Interamericana de Derechos Humanos ha subrayado la especial obligación de los Estados respecto de la efectividad de los derechos humanos de las personas vulnerables:

“...La Corte Interamericana reitera que toda persona que se encuentre en una situación de vulnerabilidad es titular de una protección especial, en razón de los deberes especiales cuyo cumplimiento por parte del Estado es necesario para satisfacer las obligaciones generales de respeto y garantía de los derechos humanos. El Tribunal recuerda que no basta con que los Estados se abstengan de violar los derechos, sino que es imperativa la adopción de medidas positivas, determinables en función de las particulares necesidades de protección del sujeto de derecho, ya sea por su condición personal o por la situación específica en que se encuentre". ${ }^{2}$

\footnotetext{
${ }^{11}$ Sentencia del 6/05/14. En este caso, la Corte ya había reconocido la situación de colapso del fuero previsional y resolvió que las causas en las que no se hubieran dictado actos "típicamente jurisdiccionales" antes del 30 de abril de 2014 debían continuar su tramitación ante las Cámaras Federales respectivas. En Constantino, la Corte ordenó la remisión de todos los expedientes, sin distinguir si habían tenido o no radicación ante la Cámara Federal de la Seguridad Social.

${ }^{12} \mathrm{CIDH}$, Furlán y familiares vs. Argentina, Sentencia de Fondo, Excepciones Preliminares, Reparaciones y Costas del 31 de agosto de 2012 y sus referencias a Masacre de Mapiripán vs. Colombia, Fondo, Reparaciones y Costas. Sentencia de 15 de septiembre de 2005. Serie C No. 134, párrs. 111 y 113, y Pueblo Indígena Kichwa de Sarayaku vs. Ecuador Fondo y reparaciones, Sentencia de 27 de junio de 2012. Serie C N²45, párr. 244.
} 


\section{LA TUTELA DE LOS ADULTOS MAYORES EN LA PROVINCIA DE CORRIENTES (ARGENTINA)}

Es importante destacar que la protección de los grupos vulnerables no es competencia exclusiva del estado nacional, sino un deber concurrente con las jurisdicciones provinciales. El sistema federal permite que los estados subnacionales dicten normas de tutela a los derechos de las personas en mayor situación de vulnerabilidad. La Constitución de la provincia de Corrientes incluyó, a partir de la reforma de 2007, en el capítulo de los nuevos derechos y garantías, una norma específica sobre las personas ancianas: "De los Derechos de la Ancianidad. Artículo 43: Ninguna persona debe ser discriminada por causa de su edad. El Estado debe garantizar a los adultos mayores la igualdad real de oportunidades, trato y pleno goce de los derechos reconocidos en esta Constitución, en la Constitución Nacional, en los Tratados y en las leyes. El Estado, mediante políticas sociales, vela por su protección e integración socio económica y cultural, tendiente a cubrir sus necesidades específicas y a elevar su calidad de vida, y provee especialmente a la protección de los ancianos que se hallen en riesgo, abandonados y desamparados, dictando políticas de inclusión de forma directa o a través de terceros". ${ }^{13}$

Con posterioridad (2013), la provincia ha dictado una norma especial de protección de los derechos de las personas mayores: La ley 6243 que crea el Sistema Integral de Protección a los Adultos Mayores. ${ }^{14} \mathrm{~A}$ continuación, examinaremos sus principales disposiciones y su relación con el resto del ordenamiento jurídico aplicable.

\section{1 Ámbito de aplicación subjetivo}

4.1.1. Sujetos tutelados ¿Quiénes son los adultos mayores? ¿Es posible fijar una edad a partir de la cual se es sujeto de protección especial? El artículo 2 de la Convención define como persona mayor a aquella de 60 años o más, salvo que la ley interna determine una edad base menor o mayor, siempre que esta no sea superior a los 65 años. En el caso de Argentina no existe una ley federal que defina a la persona adulta mayor, por lo que rige plenamente la edad supletoria prevista en la Convención (6o años). Esta edad de referencia es la misma que consagra la ley 6243 de Corrientes, sin distinción de género. ${ }^{15}$

\subsubsection{Sujetos obligados}

Los estados -tanto nacional como provincial- son los garantes de la tutela de los adultos mayores. Sin embargo, la primera obligada a garantizar el goce de sus derechos es la propia familia del adulto mayor. Este principio de subsidiariedad aparece explícito en el artículo 5

\footnotetext{
${ }^{13} \mathrm{https}$ ///www.corrientes.gov.ar/assets/articulo_adjuntos/28/original/Constitución_de_la_Provincia_de_Corrientes.pdf?1377356446

${ }^{14}$ Texto completo disponible en http://www.hcdcorrientes.gov.ar/Leyes-texto/Ley6243.pdf

${ }^{15}$ Artículo 2 la ley 6243 (Corrientes): "A los efectos de esta ley, se considera "adulto mayor" a toda persona que tenga cumplidos los sesenta (60) años de edad que resida en forma permanente en el territorio de la provincia, sin distinción de nacionalidad".
} 
de la ley 6243 de Corrientes, que establece que familia es responsable en forma prioritaria de asegurar a los adultos mayores de su grupo el disfrute pleno y efectivo de sus derechos. ${ }^{16}$ De este modo, los derechos reconocidos en la ley resultan también exigibles a los miembros de la familia que se hallan en condiciones materiales de tutelar los derechos de los adultos mayores (por la vía procesal que corresponda). ¿Es necesario acreditar que la familia no puede garantizar un derecho para exigir su cobertura por parte del Estado? Entiendo que la subsidiariedad no debe interpretarse de este modo, exigiendo pruebas negativas de difícil cumplimiento, sino como un reconocimiento de la posibilidad del titular del derecho de accionar de modo alternativo contra su propio entorno familiar o contra el ente estatal.

En relación al sujeto pasivo de las obligaciones, tanto la Convención como la ley provincial obligan de modo directo al poder legislativo (al dictado de las normas necesarias para el efectivo goce de los derechos), al poder ejecutivo (tanto en sus potestades reglamentarias como en el dictado de los actos particulares de aplicación) y al poder judicial (en sus potestades administrativas y jurisdiccionales). Dentro de la administración, son varios los entes que pueden resultar obligados, dependiendo de sus respectivas esferas de competencia. Sin embargo, dos organismos descentralizados aparecen como especialmente vinculados al cumplimiento de la tutela especial: el Instituto de la Obra Social de Corrientes (IOSCOR) y el Instituto de Previsión Social de Corrientes (IPS). El primero es el encargado de cubrir las prestaciones médicas, farmacéuticas, kinesiológicas, bioquímicas, odontológicas y de enfermería a los empleados públicos en actividad y pasivos y sus familias. Todas estas prácticas son costosas y con la elevación de la expectativa de vida se tornarán aún más complejas y onerosas. El IPS es el encargado de la liquidación y pago de los haberes previsionales del mismo grupo ocupacional. Como tal, resulta imprescindible considerar cuáles serán las políticas tendientes a asegurar el financiamiento de un número cada vez mayor de beneficiarios de jubilaciones y pensiones y que -adicionalmente- es previsible perciban sus haberes por un lapso cada vez mayor (en muchos casos más de 20 años) como consecuencia del aumento de la expectativa de vida.

Este crecimiento de los gastos en materia de seguridad social de los adultos mayores es ya evidente, como resulta de la comparación de las últimas leyes de presupuesto aprobadas en la provincia.

\begin{tabular}{|c|c|c|c|c|c|c|c|c|}
\hline \multirow[b]{3}{*}{$\begin{array}{l}\text { Instituto de } \\
\text { Previsión Social }\end{array}$} & \multicolumn{8}{|c|}{ Tabla N¹. Gastos del IPS y del IOSCOR (2012-2018) } \\
\hline & \multicolumn{2}{|c|}{ Presupuesto 2012} & \multicolumn{2}{|c|}{ Presupuesto 2014} & \multicolumn{2}{|c|}{ Presupuesto 2016} & \multicolumn{2}{|l|}{ Presupuesto 2018} \\
\hline & $\$ 1.355 .715 .829$ & $15,15 \%$ & $\$ 2.844 .149 .851$ & $18,48 \%$ & $\$ 4.879 .313 .992$ & $17,26 \%$ & $\$ 10.452 .922 .419$ & $22,11 \%$ \\
\hline $\begin{array}{l}\text { Instituto de la } \\
\text { Obra Social }\end{array}$ & $\$ 278.753 .083$ & $3,12 \%$ & $\$ 684.633 .118$ & $4,45 \%$ & $\$ 1.341 .281 .400$ & $4,74 \%$ & $\$ 2.251 .052 .267$ & $4,76 \%$ \\
\hline $\begin{array}{l}\text { Total de gastos } \\
\text { provinciales }\end{array}$ & $\$ 8.947 .677 .944$ & $100,00 \%$ & $\$ 15.387 .297 .739$ & $100,00 \%$ & $\$ 28.275 .124 .696$ & $100,00 \%$ & $\$ 47.275 .559 .420$ & $100,00 \%$ \\
\hline
\end{tabular}

Fuente: Elaboración propia en base a leyes provinciales de presupuesto 6095 (2012), 6251 (2014), 6366 (2016) y $6432(2018) .{ }^{17}$

\footnotetext{
${ }^{16}$ Este criterio ya estaba expuesto en el artículo 37 de la Constitución Nacional de 1949, norma que incluso preveía la posibilidad del Estado de subrogarse para solicitar a la familia el reintegro de los gastos realizados para la atención del adulto mayor.

${ }^{17}$ Las leyes de presupuesto se encuentran disponibles en la página de la Contaduría General de la Provincia de Corrientes http://www. cgpcorrientes.gov.ar/listas. php? $r=2 \& s=2 \& \mathrm{t}=6$
} 
Como resulta de la tabla $\mathrm{N}^{\circ} 1$, el presupuesto de los entes especialmente encargados de la atención de los adultos mayores muestra una inequívoca tendencia creciente. Más allá del aumento nominal -un incremento del 700\% en seis años- que puede ser explicado en parte por el proceso inflacionario, la importancia relativa ha crecido permanentemente. Así, de significar un $18,27 \%$ del presupuesto provincial de 2012, los entes en análisis pasan a explicar el 26,87\% del total de los gastos; esto es un incremento del $47 \%$ de su peso relativo promedio en el presupuesto $(+45,94 \%$ para el IPS y $+52,56 \%$ para el IOSCOR). Esta tendencia será potenciada por el fenómeno del envejecimiento de la población, por lo que resulta necesario prever a la mayor brevedad posible el aumento de los recursos necesarios, así como las fuentes de financiamiento para las nuevas prestaciones.

\section{DE LOS DERECHOS DE LOS ADULTOS MAYORES EN PARTICULAR}

En el capítulo anterior hemos expuesto la problemática general de la tutela de los adultos mayores. Corresponde ahora el análisis particular de los principales derechos, así como de los problemas que surgen con relación a su efectividad.

\subsection{Derecho a la vida digna y a la no discriminación por edad ${ }^{18}$}

Además de estar prohibida expresamente la discriminación por edad, la Convención reconoce expresamente el concepto de discriminación múltiple, para el caso - muy frecuente- de los sujetos vulnerables incluidos en más de un grupo de especial condición históricamente discriminado. Así deben tenerse especialmente en cuenta los casos de los que, además de adultos mayores son mujeres, personas con discapacidad, personas de orientaciones sexuales o identidades de género singulares, personas migrantes, personas en situación de pobreza o marginación social, afrodescendientes, personas pertenecientes a pueblos indígenas, personas sin hogar, personas privadas de libertad, personas pertenecientes a pueblos originarios, personas pertenecientes a grupos étnicos, raciales, nacionales, lingüísticos, religiosos y rurales, entre otros casos. En estos supuestos, el Estado deberá prever mecanismos especiales de atención y resolución preferente de la afectación de los derechos humanos, así como políticas de prevención de la discriminación. Es obligación de los organismos del Estado, la familia y la sociedad asegurar a los adultos mayores el pleno desarrollo de su proyecto de vida hasta el máximo de sus potencialidades, así como el goce de una vida plena y digna.

${ }^{18}$ Artículo 6 de la Convención y artículo 6 de la ley 6243. 


\subsection{Derecho a la autonomía ${ }^{19}$}

Los adultos mayores tienen derecho a una vida autónoma e independiente, según sus tradiciones y creencias. Para ejercer tal derecho, se debe respetar a la persona mayor en la toma de sus decisiones, así como favorecer la independencia en la realización de sus actos. Los adultos mayores deben tener la oportunidad de elegir su lugar de residencia, dónde y con quién desean vivir, en igualdad de condiciones que el resto de las personas. Para ello, la persona mayor debe tener acceso a servicios de asistencia domiciliaria, incluida la asistencia personal que sea necesaria para facilitar su existencia y evitar su aislamiento. Este derecho se relaciona directamente con la posibilidad de elegir el lugar de residencia: su propia vivienda (en condiciones dignas y con el debido acondicionamiento) o una residencia especialmente adaptada.

Según Gherardi y Zibecchi (2011, p. 111) en los últimos treinta años se ha intensificado el desplazamiento de ciertas prestaciones que antiguamente proveía el Estado hacia las familias para satisfacer necesidades de los hogares vinculadas al cuidado intergeneracional (infantil y de adultos mayores) y de otros integrantes dependientes (discapacitados). El "enfoque de derechos" subraya que los derechos reconocidos en tratados internacionales requieren medidas positivas y políticas públicas del Estado para su efectiva vigencia (Abramovich y Pautassi 2009). Pautassi (2007) destaca la importancia de considerar el derecho a los cuidados como un derecho universal asignando los recursos para su realización. En este sentido, esta autora considera necesario dejar de lado la valoración ética de la labor, que refuerza el carácter altruista adjudicado a los cuidadores (en su inmensa mayoría mujeres), para hablar de un verdadero “derecho" al cuidado.

Las obras sociales -o los organismos del estado para los casos de ausencia de cobertura- deben otorgar la cobertura progresiva y suficiente de los servicios de acompañamiento y atención domiciliaria. Sin embargo, a la fecha y en nuestra unidad de análisis, el sistema de cuidados domiciliarios, no se halla operativo. El Ministerio de Desarrollo Social de la Nación posee un listado de cuidadores domiciliarios que es accesible vía web, donde se incluye a los cuidadores disponibles en la provincia de Corrientes. ${ }^{20}$ En el orden provincial, también el Ministerio de Desarrollo Humano ha lanzado un programa de capacitación destinado a formar cuidadores domiciliarios en coordinación con el IOSCOR, pero está pendiente la instrumentación de las prestaciones a los afiliados. ${ }^{21}$

\subsection{Derecho a la integridad física y espiritual ${ }^{22}$}

Las personas mayores tienen derecho a no ser sometidas a discriminación, abuso físico o económico, trato violento, humillante o intimidatorio. De este modo, tienen derecho a su integridad física, sexual, psíquica, económica y moral, que les permita un carácter pleno de la vida. Para garantizar este derecho, el Estado debe proveer al adulto mayor de la defensa contra abusos (físi-

\footnotetext{
${ }^{19}$ Artículo 7 de la Convención y artículo 1 de la ley 6243.

${ }^{20} \mathrm{http}: / /$ registroncd.senaf.gob.ar/Default.aspx

${ }^{21} \mathrm{~A}$ la fecha, como resultado del leading case S., R. A. c/IOSCOR s/Amparo al que nos referimos más abajo, se otorga cobertura parcial -por vía de reintegro- a los cuidadores, por un importe equivalente a la atención en la residencia geriátrica con la cual el IOSCOR tiene convenio.

22 Artículos 9 y 12 de la Convención y artículo 7 de la ley 6243.
} 
cos, psicológicos o económicos) por parte de sus familiares o cuidadores. La doctrina ha señalado que entre un $3 \%$ y $10 \%$ de los ancianos sufren malos tratos, de los cuales el $37 \%$ es ejercido por los hijos, el 13\% por los cónyuges y el 11\% por otros familiares (RUBIO, 2005 p. 115). Para evitar estas situaciones, además de la necesaria difusión de los derechos, es necesario habilitar canales idóneos para la realización o tramitación de denuncias (p.e. líneas telefónicas gratuitas) realizadas por los mismos afectados o cualquier persona que tome conocimiento de los malos tratos.

\subsection{Derecho a la privacidad ${ }^{23}$}

Los adultos mayores tienen derecho a la vida privada y a la intimidad de su vida familiar. Para garantizar esta privacidad, es necesario que se respete su espacio físico dentro del entorno familiar, sus horarios y costumbres, y sus objetos personales. En el caso de una situación de institucionalización, sea en institutos geriátricos o de salud, los organismos del Estado deben garantizar a las personas mayores el vínculo y el contacto directo y permanente con sus familias y amistades. Del mismo modo, el Estado es responsable que los establecimientos que alojan ancianos cumplan con toda la normativa sanitaria, edilicia y de capacitación del personal encargado, para que este derecho no sea ilusorio.

\subsection{Derecho a la salud ${ }^{24}$}

Los organismos del Estado deben garantizar el acceso a servicios de salud (considerada en sentido amplio) para los adultos mayores y para sus familias. Las personas mayores tienen derecho una atención integral de su salud, a recibir la asistencia médica necesaria y a acceder en igualdad de oportunidades a los servicios y acciones de prevención, promoción, información, protección, diagnóstico precoz, tratamiento oportuno y recuperación de la salud. Del mismo modo, deben preverse programas que garanticen el derecho de todos los adultos mayores a la recreación, al esparcimiento, al turismo y al acceso a un ambiente sano y equilibrado, a la preservación y disfrute del paisaje. En este sentido, debe otorgarse a los adultos mayores una atención preferente y más completa que la básica ya prevista para el caso de personas no vulnerables. ${ }^{25}$

\subsection{Derecho a la libertad ${ }^{26}$}

Este derecho comprende no solo a la libertad ambulatoria, sino también los derechos a tener sus propias ideas, creencias o culto, a expresar su opinión en los ámbitos de su vida cotidiana y en la comunidad. También tienen derecho a participar y expresar libremente su opinión

\footnotetext{
${ }^{23}$ Artículo 16 de la Convención y artículo 8 de la ley 6243.

${ }^{24}$ Artículos 11 y 19 de la Convención y artículo 10 de la ley 6243.

${ }^{25}$ Pacto Internacional de Derechos Económicos, Sociales y Culturales, Artículo 121 . Los Estados Partes en el presente Pacto reconocen el derecho de toda persona al disfrute del más alto nivel posible de salud física y mental.

${ }^{26}$ Artículo 12 de la Convención y artículo 12 de la ley 6243.
} 
en todos los asuntos que les conciernan y en aquellos que tengan interés; y a que sus opiniones sean tenidas en cuenta conforme su capacidad. Otro derecho que debe ser garantizado es el acceso a las nuevas tecnologías y a la educación tecnológica. Para hacer efectiva esta posibilidad, debe preverse la debida capacitación y asistencia, de un modo que sea asequible para los adultos mayores. Además, en materia de libertad ambulatoria, debe garantizarse el acceso físico a las dependencias públicas, de manera progresiva y continua, eliminando obstáculos físicos y dotando a los espacios públicos de un entorno amigable para personas ancianas o con dificultades en su desplazamiento (ascensores, rampas, baños adaptados, sillas confortables para espera, etc.).

\subsection{Derecho al trabajo ${ }^{27}$}

Los organismos del Estado deben garantizar el derecho de las personas mayores a trabajar en aquellas tareas que puedan realizar sin discriminación en razón de su edad y reconocer su experiencia, conocimientos y capacidad de aprendizaje. El trabajo de los adultos mayores debe lograr un equilibrio entre el legítimo derecho al descanso de aquellos que ya han cumplido con su ciclo de aporte productivo, con el de aquellos que pueden o desean seguir aportando a la creación de riqueza o conocimiento desde su experiencia, pero sin que por ello se impida la necesaria renovación de los planteles laborales.

\subsection{Derecho a la seguridad social. ${ }^{28}$}

El estado deber garantizar el acceso de los adultos mayores a las prestaciones de la seguridad social que por imperio del artículo 14 bis de la Constitución Nacional debe ser integral e irrenunciable. Esta cobertura general no impide que se establezcan requisitos de edad y antigüedad para acceder a los distintos beneficios (p.e. la jubilación). Pero aun en el caso de que no se cumplimenten todos los requisitos formales para el otorgamiento de los beneficios, el estado debe garantizar un mínimo de cobertura a los adultos mayores. ${ }^{29}$ La previsión social en la provincia de Corrientes se halla regulada por la ley $4917^{30}$ y sus modificatorias. Como ya mencionamos más arriba, el órgano de aplicación del sistema previsional en la provincia de Corrientes es el Instituto de Previsión Social, un ente descentralizado encargado del otorgamiento, liquidación y pago de las jubilaciones y pensiones. ${ }^{31}$

\footnotetext{
${ }^{27}$ Artículo 18 de la Convención y artículo 16 de la ley 6243.

28 Artículo 17 de la Convención y artículo 17 de la ley 6243.

${ }^{29}$ Como lo ha sostenido la Organización Mundial de la Salud. Ver boletín disponible en http://www.who.int/bulletin/ volumes/96/1/17-204214/es/

${ }^{30} \mathrm{http}: / /$ www.hcdcorrientes.gov.ar/Leyes-texto/Ley4917.pdf

${ }^{31} \mathrm{http}: / /$ www.ipscorrientes.gov.ar/
} 


\section{LOS CRITERIOS DE INTERPRETACIÓN HERMENÉUTICA DE LAS NORMAS DE TUTELA DE LAS PERSONAS MAYORES}

Entre los sistemas de protección nacional y supranacional y aquel que es propio del estado provincial, existe - más allá del objeto de tutela común- una necesaria doble consideración en cuanto a la ley aplicable. Desde el punto de vista de la jerarquía normativa, es indudable que la Convención posee rango superior (lex superior) a tenor de lo dispuesto en el artículo $31 \mathrm{de}$ la Constitución Nacional. También desde un punto de vista cronológico posee preeminencia, por tratarse de una ley posterior (lex posterior derogat priori). Sin embargo, la ley provincial posee un ámbito de aplicación naturalmente acotado a su propia jurisdicción (la provincia de Corrientes) y por tanto se trata de una lex specialis.

Por lo tanto, para resolver los posibles conflictos de doble regulación, y sin dejar de considerar el carácter de norma suprema de la Convención, es que deben aplicarse principios hermenéuticos comunes a los tratados de derechos humanos:

a) El principio pro homine o pro persona, común a todo el bloque de Derechos Humanos y reconocido en el propio artículo 1 del tratado, según el cual en caso de conflicto entre dos normas debe aplicarse aquella que contenga mayores protecciones o condiciones más favorables para el derecho del individuo. Así lo ha sostenido reiteradamente la Corte Suprema de Justicia de la Nación: "El principio pro homine o pro persona, que "informa todo el derecho de los derechos humanos" (Portal de Belén, Fallos: 325:292, 306 -2002-) y que resulta "connatural" con el Derecho Internacional de los Derechos Humanos (Madorrán, Fallos: 330:1989, 2004-2007), "impone privilegiar la interpretación legal que más derechos acuerde al ser humano frente al poder estatal" (Acosta, Fallos: 331:858, 864-2008-)". ${ }^{22}$

b) El principio de progresividad en virtud del cual, una vez que un derecho ha sido reconocido por el Estado, no es posible que luego, por leyes o por actos administrativos posteriores, se los desconozca, posponga su goce o de cualquier otra manera se disminuya el grado de protección ya alcanzado..$^{33}$ La progresividad también implica que los Estados deben ir ampliando constantemente -y en la medida de sus posibilidades- el ámbito de ejercicio y la plenitud del derecho. Este principio aparece expresamente reconocido en los artículos 4, 7, 17, 19, 20, 24, 32, 35 y 36 de la Convención. En consecuencia, ante una situación en la que exista duda respecto de la existencia o no de un derecho del adulto mayor, deberá siempre estarse a la interpretación que otorgue una mayor protección o extensión al derecho.

c) Los principios que inspiran a la Convención, y que deben guiar su interpretación y la de toda la normativa de tutela de los adultos mayores, son los de la valorización de la

\footnotetext{
${ }_{32}$ CSJN, en autos Carranza Latrubesse, Gustavo c/Estado Nacional - Provincia de Chubut, sentencia del 6/08/13, considerando 16 del voto de la mayoría.

${ }^{33}$ CSJN, en autos Sánchez, María del Carmen c/ ANSeS s/reajustes varios sentencia del 28/07/05.
} 
persona mayor, su dignidad, independencia y autonomía. También son principios de interpretación la igualdad y la no discriminación, la integración efectiva en la sociedad, el buen trato y la atención preferencial y la protección judicial efectiva. En consecuencia, en caso de duda o ausencia de normativa específica, se debe dar preeminencia a aquella interpretación que mejor respete la plena vigencia de estos principios.

Sin perjuicio de los criterios expuestos, la jurisprudencia de los tribunales correntinos a la que nos referiremos en el capítulo siguiente, demuestra que no existen obstáculos jurídicamente válidos para efectivizar la tutela de los adultos mayores, aún en el supuesto de ausencia de norma expresa de protección.

\section{LA TUTELA DE LOS DERECHOS DE LOS ADULTOS EN LA JURISPRUDENCIA DE LOS TRIBUNALES DE LA PROVINCIA DE CORRIENTES}

En la provincia de Corrientes, y como consecuencia de la reciente vigencia del plexo normativo que venimos detallando, no existe una jurisprudencia consolidada sobre la tutela especial de los adultos. Sin embargo, se destacan los siguientes casos:

\subsection{Fallo del Superior Tribunal de Justicia de la provincia de Corrientes, en autos} G. de R. M. S. c. G. M. I. y/o C. O. O. Expte. No 57508/10 (28/11/2012)

Hechos del caso: Una mujer de 89 años de edad que convivía con su nuera y los cuatro hijos de esta era víctima de violencia psíquica y física de parte de ellos. A raíz de esto, solicitó una medida cautelar que los excluya del hogar. El tribunal de primera instancia hizo lugar a la petición y la Cámara confirmó lo resuelto. El Superior Tribunal de Justicia de Corrientes declaró inadmisible el recurso extraordinario y confirmó ambos fallos. Para ello, el tribunal sostuvo acertadamente que:

"La adicción a las drogas de sus hijos mayores no puede aceptarse por los tribunales de justicia como excusa válida para mantenerlos conviviendo con la abuela octogenaria a quien maltratan. Y situados frente a la gravedad y urgencia de la situación del caso, parece irrazonable la pretensión de colocar a la anciana peticionaria ante la única alternativa de acudir a la previa vía judicial prevista por el tercer párrafo del artículo 482 el Código Civil para obtener la exclusión de aquellos de su domicilio, cuando mediante este proceso ya lleva más de dos años litigando y quien pretende esa solución es la madre de los toxicómanos... En este contexto, y si la recurrente ha reconocido tácitamente -al no someter a crítica concreta- la interpretación de los jueces de grado acerca de que atañe a los magistrados buscar oficiosamente soluciones que se avengan 
con la urgencia que conlleva la situación de una anciana maltratada, es fácil comprender que el correlativo derecho se frustraría si la abuela tuviese que aguardar al inicio del trámite a que se refiere el artículo 482 del Código Civil, y en ese lapso hasta la orden judicial de internación su equilibrio psíquico emocional gravemente afectado por la convivencia de ella con los nietos adictos, y que ya ha puesto en riesgo su salud mental [...] quedaran desprotegidos... La solidaridad familiar entre parientes no puede poner en riesgo la propia subsistencia de la alimentante, más cuando es obvio, por su edad, que ya no puede procurarse por sí misma mayores ingresos; a diferencia de lo que sucede con la madre de las niñas, de 42 años de edad. Está fuera de duda que los menores merecen amparo. Más igualmente necesario es brindar protección a quien ya está en la tercera edad" (del voto del ministro Semhan, al que adhirieron los ministros Niz y Chain).

\subsection{Fallo de la Cámara de Apelaciones en lo Civil y Comercial de Corrientes, Sala Cuatro en autos $S$. de S., F. Expte. No 246840 (Sentencia del 5/12/2013)}

Hechos del caso: Una mujer de 82 años inició una acción negatoria con el fin de permanecer en el inmueble que constituía su hogar conyugal. El tribunal de primera instancia, después de valorar la inactividad de la actora, declaró la caducidad de la instancia. La accionante interpuso recurso de apelación. La Sala Cuatro de la Cámara de Apelaciones en lo Civil y Comercial de Corrientes hizo lugar al recurso y revocó la decisión del juez de primera instancia. El tribunal de alzada sostuvo que "Las 100 Reglas de Brasilia (Adoptadas por la República Argentina por el Bloque de Defensores Oficiales y con recomendación de aplicación a los máximos organismos jurisdiccionales de los países integrantes del MERCOSUR, como así también a los distintos Superiores Tribunales o Cortes de Justicia de las distintas Provincias en su implementación, conforme la XIV Cumbre Judicial Iberoamericana celebrada durante el primer semestre de 2008 en la ciudad de Brasilia, República Federativa del Brasil) resultan de aplicación en los casos en que un adulto mayor se encuentre en situación de posible desprotección o fragilidad, buscando de este modo garantizar la eficacia de sus derechos, y lograr así una igualdad real y no tan solo formal" (voto del juez Rodríguez al que adhirió el juez Monferrer). "Se ha sostenido que la mayor presencia física de ancianos hace que tengamos que repensar su condición de sujeto de derecho, a fin de poder situarlo ante la ley realmente en igual posición que los demás. Esta aceptación también nos habla de fortalecer el reconocimiento de sus derechos a fin de que funcionen como verdaderos derechos subjetivos. A tal fin, la ancianidad debería ser calificada como una diferencia relevante, tanto a la hora de legislar como a la sentenciar" (voto del juez Rodríguez al que adhirió el juez Monferrer).

7•3. Fallo de la Cámara de Apelaciones en lo Civil y Comercial de Corrientes, Sala Cuatro en autos O., O. L. c/Aguas de Corrientes S.A. s/Sumarísimo, Expte. No 63375 (Sentencia del 5/2/2014)

Hechos del caso: El actor solicitó la reparación del servicio de cloaca su domicilio, sin cargo alguno. Manifestó que habiendo detectado una obstrucción del servicio cloacal efectuó reclamo a 
la empresa prestataria quien concurrió a su domicilio y constató que la conexión cloacal se había desplazado en la vereda debido al crecimiento de la raíz de un árbol, lo que produjo la rotura de los caños cloacales y el estancamiento de los fluidos lo que, a su vez, llevó a la privación del uso de los sanitarios por parte de todo su grupo familiar. La sentencia de primera instancia hizo lugar a la acción interpuesta y en su mérito, ordenó a Aguas de Corrientes S.A. a hacerse cargo de los gastos que originó la total reparación de la red cloacal domiciliaria correspondiente al accionante

La Cámara confirmó el fallo. Sostuvo que:

"La Constitución Nacional impone en su Art. $75^{\circ}$ inc. 23, que en el caso de las acciones en relación a los ancianos y personas con discapacidad, se deben promover "acciones positivas" tendientes a la protección de sus derechos. En igual sentido la Constitución de la Provincia de Corrientes establece la obligación del Estado de garantizar a los adultos mayores la igualdad real de oportunidades y de trato y el pleno goce de los derechos reconocidos en la Constitución Provincial, la Constitución Nacional, los Tratados Internacionales sobre DD.HH. y las 100 Reglas de Brasilia... Que la mayor presencia física de ancianos hace que tengamos que repensar su condición de sujeto de derecho, a fin de poder situarlo ante la ley realmente en igual posición que los demás. Esta aceptación también nos habla de fortalecer el reconocimiento de sus derechos a fin de que funcionen como verdaderos derechos subjetivos. A tal fin, la ancianidad debería ser calificada como una diferencia relevante, tanto a la hora de legislar como a la de sentenciar. Entre las causas que pueden constituir vulnerabilidad considera la edad (Reglas 3 y 4) y a su vez encuadra a la ancianidad como grupo vulnerable, en atención a que establece que "El envejecimiento también puede constituir una causa de vulnerabilidad cuando la persona adulta mayor encuentra especiales dificultades, atendiendo a sus capacidades funcionales para ejercitar sus derechos ante el sistema de justicia” (Sección 2, punto 1,6)- (Conf. Dabove, María Isolina y Padilla, María del Carmen, "El Acceso a la Justicia de la Vejez, a la luz de las "1oo Reglas de Brasilia”, en Nogueira, Juan Martín y Chapiro, Hernán, Acceso a la Justicia y Grupos Vulnerables, A propósito de las Reglas de Brasilia, Ed. Librería Platense, La Plata, 2012 ,pp.146/147). El Estado Social de Derecho, no puede ser el producto de excesos rituales ante una parte vulnerable que evidentemente intenta hacer valer sus derechos (Del voto del Dr. Carlos A. Rodriguez, al que adhiere el Dr. Rosendo Monferrrer).

\subsection{Fallo de la Cámara Contencioso Administrativa en autos $S$., R. A. c/Ioscor s/ Amparo Expte. 100362/14, Resolución del 09/05/14}

Hechos del caso: La actora, una viuda que vivía sola y que padecía de enfermedad de Parkinson y Diabetes Tipo II solicitó la cobertura -al menos parcial- de los gastos de las cuatro acompañantes con los que debía contar -en turnos rotativos-durante las 24 horas. Denegado el pedido en sede administrativa, promovió una acción de amparo y solicitó una medida cautelar. El juzgado de primera instancia (Civil y Comercial $\mathrm{N}^{\circ} 1$ de Corrientes) declaró inadmisible la acción. Contra esta resolución, la actora interpuso recurso de apelación. Llegado a la 
Cámara de Apelaciones en lo Contencioso Administrativo, y en el marco de una audiencia de conciliación, el IOSCOR reconoció el reintegro parcial de los gastos de las cuidadoras, hasta el monto equivalente al que reconocía por la internación en establecimientos gerontológicos.

Este precedente es muy importante, ya que con posterioridad al mismo, el IOSCOR comenzó a reconocer las peticiones administrativas de reintegro de los gastos de cuidadores, hasta el valor de convenio de las residencias geriátricas (a la fecha del fallo, \$6.00o).

\subsection{Fallo del Juzgado de Paz de la localidad de Mocoretá (Corrientes) en autos L.R. s/ Protección de Persona, Expte. № 669/17, Resolución del 18/o5/17}

Hechos del caso: La causa se inició con la denuncia de una nieta de R.L. quien cuestionó las circunstancias en las que vivía su abuela. La mujer, que padecía artrosis, hipertensión arterial y problemas de desplazamiento, habitaba una humilde vivienda con uno de sus hijos, encargado de cobrar su jubilación y brindarle asistencia. Tenía además otros seis hijos que, citados por el juzgado, coincidieron en la falta de higiene del lugar y en la precariedad de la casa. El magistrado dictó una medida cautelar de protección de la persona mayor: Impuso a los hijos que velaran por el cuidado de su madre en forma conjunta; que periódicamente se la llevara al médico y al odontólogo; que se adecuara la vivienda (cambio de letrina, acondicionamiento de ventanas, obtención de un medio de calefacción), para evitar cualquier riesgo y/o afección a la salud respiratoria. El doctor Podestá ordenó además al hijo conviviente retirar todas las mercaderías que le brinda el PAMI a su madre y proveer una nutrición adecuada. Todas estas obligaciones debían cumplirse, bajo apercibimiento de dar intervención a la Fiscalía de Instrucción. Al fundar la medida cautelar, el magistrado aplicó la Convención Internacional de Protección de las Personas Mayores (arts. 2, 3, 12, 19 y 31). El fallo es valioso, sin perjuicio de que a la fecha de su dictado, la Convención aún no se hallaba vigente (no había sido publicada en el Boletín Oficial la ley de ratificación), de modo que la tutela podía garantizarse con base a la ley provincial, que como vimos reconoce derechos similares a los adultos mayores.

\section{ORGANISMOS ESPECIALES DE TUTELA DE LOS ADULTOS MAYORES EN LA PROVINCIA DE CORRIENTES}

Sin perjuicio del carácter operativo de los derechos de los adultos mayores, y de la consiguiente posibilidad de reclamar su cumplimiento efectivo a las autoridades administrativas y judiciales, la ley provincial 6243 ha creado órganos encargados que de manera especial deben dar tutela a tales derechos. Para ello se han establecido tres organismos: el Consejo Participativo Provincial del Adulto Mayor, la Dirección Provincial de Política para Adultos Mayores y el Defensor de los Derechos de los Adultos Mayores. 
La Dirección de Política para Adultos Mayores es un organismo creado en el ámbito de la Secretaría de Desarrollo Humano, que debe actuar como el organismo específico en materia de derechos de las personas mayores y ejecución de políticas públicas de su competencia.

El Consejo Participativo Provincial del Adulto Mayor está integrado por quien ejerza la titularidad de la Dirección Provincial del Adulto Mayor (quien lo preside), por los representantes de las instituciones que se dediquen directa o indirectamente al cuidado y atención de las personas mayores, y por los órganos existentes o a crearse en los municipios. El Consejo tendrá funciones deliberativas, consultivas, de formulación de propuestas y de políticas de concertación, canalizando las iniciativas de los adultos mayores. Este Consejo es un medio de participación de la comunidad en la definición y ejecución de las políticas públicas.

El Defensor de los Derechos de los Adultos Mayores tiene como función la protección y promoción de los derechos de las personas mayores. El Defensor debe ser propuesto, designado y removido por la Legislatura Provincial, dura cinco años en sus funciones y puede ser reelegido una sola vez. Sus funciones son las de brindar asesoramiento, recibir todo tipo de reclamo formulado por los adultos mayores o cualquier denuncia, propiciar instancias de conciliación o mediación, promover los reclamos administrativos y las acciones judiciales que correspondan para la protección de los intereses colectivos o individuales de los adultos mayores. El Defensor deberá dar cuenta anualmente a la Legislatura provincial, de la labor realizada en un informe que presentará antes del 31 de mayo de cada año.

Estos tres órganos tienen como función específica la defensa de los derechos de los adultos mayores, sin perjuicio de la competencia del resto de la administración central y de los entes autárquicos. Sin embargo, más allá de las previsiones legales, transcurridos más de 5 años de sanción de la ley, ninguno de estos entes de tutela especial ha sido creado lo que evidencia un divorcio importante entre la faz normativa y la realidad de la tutela preferencial en el orden provincial.

\section{CONCLUSIONES}

La protección de los derechos de los adultos mayores en la provincia de Corrientes debe ser interpretada y aplicada como un verdadero sistema de protección de sujetos especialmente vulnerables. De este modo, los derechos especialmente reconocidos en la Convención de los derechos de los Adultos mayores, la ley provincial 6243 y el resto del ordenamiento jurídico no deben considerarse de modo aislado, sino integrando al bloque de Derechos Humanos y Sociales, que debe ser interpretado siempre en el modo más favorable a la tutela de los derechos de los mayores (principio pro homine).

Los múltiples desafíos que genera el alargamiento de la vida y el cada vez mayor número de adultos mayores deben ser abordados con urgencia, a fin de lograr un efectivo ejercicio 
de los derechos y no convertirlos en meras declaraciones retóricas, pero sin aplicación a la realidad.

Esta extensión de los derechos de las personas requiere también una necesaria previsión de los costos económicos y financieros para hacerles frente. El mero reconocimiento de derechos sin considerar como se hará frente a las mayores erogaciones que de ellos se derivan puede ser aún más regresivo que no reconocerlos. Existe una ilusión de que las prestaciones estatales no implican costos, cuando, como lo ha destacado la doctrina, incluso las meras omisiones tienen un costo económico mensurable y un derecho legal sólo existe sí y cuando tiene costos presupuestarios (Holmes - Sustein, 2010).

Sin embargo, y a pesar de la importancia cada vez mayor del problema de los derechos de los adultos mayores, se advierte una demora en incorporar su discusión a la agenda pública. Esta mora resulta evidente en el caso de nuestra unidad de análisis, donde a más de cinco años de su creación legal, no se ha puesto en funcionamiento ninguno de los órganos de tutela especial de los adultos mayores. Otra tarea pendiente del Estado es difundir los derechos de los mayores, a través de campañas generales y especialmente destinadas a los sujetos especialmente vulnerables y sus familias. Para ello, deberán tener especial protagonismo tanto el Instituto de Previsión Social, que cuenta con una base de datos donde se registran todos los adultos mayores titulares de beneficios previsionales de orden provincial y el Instituto de la Obra Social de Corrientes, como prestador de los servicios médicos, farmacéuticos, de enfermería y de asistencia a la salud de los ancianos vinculados directamente o indirectamente a la administración provincial.

Para finalizar, es muy importante subrayar que los derechos reconocidos tanto en la Convención como en la ley provincial de tutela de los adultos mayores son operativos. Es decir, que se trata de derechos exigibles por los ancianos y sus familias. Por lo tanto, la falta de respuesta de los organismos estatales habilita a los legitimados las instancias de reclamo por medios administrativos o judiciales.

\section{REFERENCIAS BIBLIOGRÁFICAS}

ABRAMOVICH, Víctor y PAUTASSI, Laura (2009) La revisión judicial de las políticas sociales. Estudios de casos. Buenos Aires, Editores del Puerto.

DAVOBE, María Isolina (2015) Derechos humanos de las personas mayores. Acceso a la justicia y protección internacional, Buenos Aires, Astrea.

DAVOBE, María Isolina (2002) Los derechos de los ancianos, Buenos Aires, Ciudad Argentina. 
GELLI, María Angélica (2013) Constitución de la Nación Argentina comentada y concorda$d a$, ta. ed. ampliada y actualizada, Buenos Aires, La Ley.

GHERARDI, Natalia y ZIBECCHI, Carla (2011) El derecho al cuidado: ¿Una nueva cuestión social ante los tribunales de justicia de Argentina? Política. Revista de Ciencia Política, 49 (1), pp. 107/138. https://www.researchgate.net/publication/272770436_El_derecho_al_ cuidado_Una_nueva_cuestion_social_ante_los_tribunales_de_justicia_de_Argentina

HOLMES, Stephen - SUNSTEIN, Cass (2010) El costo de los derechos, Buenos Aires, Siglo XXI.

HUENCHUAN, Sandra (2012), Los derechos de las personas mayores en el siglo XXI: Situación, experiencia y desafíos, México, CEPAL.

Instituto Nacional de Estadística y Censos (2014) Encuesta Nacional sobre Calidad de Vida de Adultos Mayores 2012, $1^{\mathrm{a}}$ ed., Ciudad Autónoma de Buenos Aires, INDEC.

PAUTASSI, Laura (2007) El cuidado como cuestión social: una aproximación desde el enfoque de derechos, Serie Mujer y Desarrollo 87. Santiago de Chile: CEPAL.

RUBIO, Ramona (2005) Concepto, tipos, incidencia y factores de riesgo del maltrato institucional de personas mayores en IBORRA MARMOLEJO, Isabel (ed.): Violencia contra las personas mayores, Barcelona, Ariel.

\section{COMO CITAR ESTE ARTÍCULO:}

GOLDFARB, Mauricio. Régimen de protección de los adultos mayores en la provincia de Corrientes, Argentina. Revista de la Facultad de Ciencias Económicas - UNNE. Número 20, otoño 2018, ISSN 1668 -6365. Págs. 163-185. DOI: http://dx.doi.org/10.30972/rfce.0203260 


\section{CURRICULUM VITAE}

\section{Mauricio Goldfarb}

Abogado (UNNE, 1994) Especialista en Derecho Administrativo (UNNE, 2012) y Doctor en Derecho (UNNE, 2017).

Docente de la Cátedra A de Derecho Administrativo I, Facultad de Derecho y Ciencias Sociales y Políticas, Universidad Nacional del Nordeste, Argentina.

estudiogoldfarb@hotmail.com 